\section{REFERENCES}

Canolty, R. T., Edwards, E., Dalal, S. S., Soltani, M., Nagarajan, S. S., Kirsch, H. E., Berger, M. S., Barbaro, N. M., and Knight, R. T. (2006). High gamma power is phase-locked to theta oscillations in human neocortex. Science 313, 1626-1628.

Demiralp, T., Bayraktaroglu, Z., Lenz, D., Junge, S., Busch, N.A., Maess, B., Ergen, M., and Herrmann, C. S. (2007). Gamma amplitudes are coupled to theta phase in human EEG during visual perception. Int. J. Psychophysiol. 64, 24-30.

Fell, J., Klaver, P., Elfadil, H., Schaller, C., Elger, C. E., and Fernández, G. (2003). Rhinal-hippocampal theta coherence during declarative memory formation: interaction with gamma synchronization? Eur. J. Neurosci. 17, 1082-1088.

Fries, P., Nikolić, D., and Singer, W. (2007). The gamma cycle. Trends Neurosci. 30, 309-316.

Mormann, F., Fell, J., Axmacher, N., Weber, B., Lehnertz, K., Elger, C. E., and Fernández, G. (2005). Phase/amplitude reset and theta-gamma interaction in the human medial temporal lobe during a continuous word recognition memory task. Hippocampus 15, 890-900.

Mormann, F., Osterhage H., Andrzejak R. G., Weber, B., Fernández, G., Fell, J., Elger, C. E., and Lehnertz, K. (2008). Independent delta/theta rhythms in the human hippocampus and entorhinal cortex. Front. Hum. Neurosci. 2, 3. doi: 10.3389/neuro.09.003.2008.
O’Keefe, J., and Recce, M. L. (1993). Phase relationship between hippocampal place units and the EEG theta rhythm. Hippocampus 3, 317-330.

Received: 05 November 2008; published: 15 December 2008

Citation: Front. Neurosci. (2008) 2, 2: 132-133. doi: 10.3389/neuro.01.045.2008

Copyright: (c) 2008 Heinze. This is an open-access publication subject to an exclusive license agreement between the authors and the Frontiers Research Foundation, which permits unrestricted use, distribution, and reproduction in any medium, provided the original authors and source are credited.

\title{
Looking inward: the mind's eye focuses on mental representations
}

\section{George R. Mangun* \\ Center for Mind and Brain, and Departments of Psychology and Neurology, University of California, Davis, USA \\ *Correspondence: mangun@ucdavis.edu}

\section{A commentary on}

Spatial attention can bias search in visual short-term memory

by Anna C. Nobre, Ivan C. Griffin and Anling Rao

In his visionary writings in the 19th century, American psychologist James (1890) wrote about attention describing it in part as:

"...the taking possession of the mind, in clear and vivid form, one out of what seem several simultaneously possible objects or trains of thought."

Over the course of the ensuing century, especially in the past 60 years, researchers investigating the mechanisms of attention have identified important behavioral and neural correlates of attention, which include the findings that attention influences the processing of sensory stimuli by improving perception and performance for attended stimuli versus unattended stimuli (e.g., Cherry, 1953; Posner, 1978), and that such effects can involve changes in sensory-neural signals early in the sensory hierarchy for auditory (e.g., Hillyard et al., 1973), visual (e.g., Van Voorhis and Hillyard, 1977) and somatosensory (e.g., Desmedt and Robertson, 1977) stimuli.

However, as James' quote makes it clear, selective attention not only involves select- ing between competing external signals, but also acting to select between internal and external signals, and perhaps as well between competing internal signals held in short- or long-term memory stores. I recall vividly that my late father George H. Mangun, a biochemist, could withdraw almost completely from the welter of our living room when my brother, sister and I were engaged in childhood mischief and mayhem. When he was focused on a difficult scientific problem, we had to physically leap on him to capture his attention. I asked him about this once, in amazement of his formidable mental sound-proofing, and he told me that he perfected the skill in college in order to study without being distracted. As a child I was not wholly convinced, but as an attention researcher (and a parent of two young boys myself!), I now understand the powerful nature of the human attention system for modulating sensory processing. Surprisingly, in contrast to work on the effects of attention on sensory inputs, very little work has addressed how attention can be turned inward to select from purely mental representations. There is no doubt that this paucity of research has to do with the simple fact that it is challenging to develop reliable measures of mental representations in the first place, and still harder to measure how such representations may be affected by other cognitive factors such as momentary attention.

Nobre et al. (2008), building on their and others' earlier work, have conducted a very interesting study that does just this; they have investigated, using behavioral and physiological measures, the effects of attention on representations held in one form of mental store - visual short term memory (VSTM). VSTM is a short-term (a few seconds) limited-capacity store of visual information (e.g., Zhang and Luck, 2008). Nobre et al. (2008) investigated whether the retrieval of information from VSTM could be influenced by focused attention. The authors utilized a paradigm similar to those used in studies of the effects of covert selective attention on vision using predictive precues (e.g., Mangun and Hillyard, 1991). However, instead of precuing the location to which attention should be directed in future, the authors used retrodictive cues (spatial retro-cues) that indicated the location of a relevant target in an array presented in the past (1-2 s previously) with $100 \%$ probability. In comparison to neutral retro-cues that gave no information about the likely location in the array of the relevant item, performance to indicate whether a subsequently presented probe stimulus had in fact been anywhere in the array was improved with the spatial retro-cues. Importantly, the 
spatial retro-cues were found to increasingly benefit the observers when the number of items in the array increased.

Recordings of event-related potentials (ERPs) also revealed brain potentials related to search in VSTM. Nobre et al. (2008) found a brain potential and labeled it the $\mathrm{N}_{\mathrm{RS}}$, which showed systematic changes in amplitude and duration that mirrored the behavioral findings during search. Interestingly, the ERP covaried with the degree of search required during the neutral retro-cue trials in which subjects did not benefit from retrodictive spatial cues.

Overall, the findings add support to the idea that voluntary attention can influence internal mental processing, like search through VSTM. Models that argue for immutable storage of VSTM are not compatible with the findings. However, the research suggests that William James' intro- spections on attention are as rich as they appear at first reading, and that the focus of the mind's eye can be turned inward, to affect internal mental processes, as well as outward to modulate the processing of sensory inputs from the world around us.

\section{REFERENCES}

Cherry, E. C. (1953). Some experiments on the recognition of speech, with one and two ears. J. Acoust. Soc. Am. 25, 975-979.

Desmedt, J., and Robertson, D. (1977). Differential enhancement of early and late components of the cerebral somatosensory evoked potentials during forced-paced cognitive tasks in man. J. Physiol. 271, 761-782.

Hillyard, S., Hink, R., Schwent, V., and Picton, T. (1973). Electrical signs of selective attention in the human brain. Science 182, 177-180.

James, W. (1890). Principles of Psychology. New York, H. Holt.

Mangun, G. R., and Hillyard, S. A. (1991). Modulation of sensory-evoked brain potentials provide evidence for changes in perceptual processing during visual-spatial priming. J. Exp. Psychol. Hum. Percept. Perform. 17, 1057-1074.

Nobre, A. C., Griffin, I. C., and Rao, A. (2008). Spatial attention can bias search in visual short-term memory. Front. Hum. Neurosci. 1, 1-9.

Posner, M. I. (1978). Chronometric Explorations of Mind. Oxford, UK, Lawrence Erlbaum.

Van Voorhis, S., and Hillyard, S. (1977). Visual evoked potentials and selective attention to points in space. Percept. Psychophys. 22, 54-62.

Zhang, W., and Luck, S. (2008). Discrete fixed representations in visual working memory. Nature 453, 233-235.

Received: 22 October 2008; published: 15 December 2008

Citation: Front. Neurosci. (2008) 2, 2: 133-134. doi 10.3389/neuro.01.044.2008

Copyright: () 2008 Mangun. This is an open-access publication subject to an exclusive license agreement between the authors and the Frontiers Research Foundation, which permits unrestricted use, distribution, and reproduction in any medium, provided the original authors and source are credited.

\section{Adding complexity to emotion-cognition interactions: the stressed individual}

\section{Carmen Sandi*}

Brain Mind Institute, Ecole Polytechnique Federale de Lausanne, Lausanne, Switzerland

* Correspondence: sandi@epfl.ch

\section{A commentary on}

Emotion and cognition in high and low stress-sensitive mouse strains: a combined neuroendocrine a behavioral study in $\mathrm{BALB} / \mathrm{c}$ and $\mathrm{C} 57 \mathrm{BL} / 6 \mathrm{~J}$ mice

by Vera Brinks, Maaike van der Mark, Ronald de Kloet and Melly Oitzl

Emotion and cognition were not long ago considered as independent brain functions with respective underlying neural systems working in parallel and only occasionally interacting. This earlier perspective considered that the main focus of Behavioral Neuroscience was to understand the neurobiological basis of cognition, which was considered as a "cold" mode of brain functioning. "Hot" emotional systems were regarded as inferior and not central for the eventual understanding of how the human brain works. This view has drastically changed in the past two decades with an increasing number of studies pointing out not only to a close interaction between emotion and cognition, but also to their true integration in the production of behavior (Pessoa, 2008).

Fearful experiences usually become part of our strongest memories. The uneasiness we feel when having difficulties to take a decision in a family-relevant conflict can greatly determine our ability to eventually choose an appropriate solution. These are just two examples of how the intricacy between the so-called emotional and cognitive functions really operates together. In recent years, much progress has been done both on the phenomenological characterization of such interplay and on the identification of the neural circuits and molecules that sustain cognitive-emotional behaviors (Phelps and LeDoux, 2005; Richter-Levin and Akirav, 2003); however, there are at least two key issues to understand the whole picture that has been so far largely disregarded. One issue is the key standing role of stress systems. The other issue is the question of individual dif- ferences and how the differences can affect stress-cognitive-emotional interactions.

In a research report published in Frontiers in Behavioral Neuroscience, Brinks et al. (2007) have specifically addressed these two key issues. The authors took advantage of the known drastic differences in the responsiveness of stress systems in two inbred strains of mice, $\mathrm{BALB} / \mathrm{c}$ and $\mathrm{C} 57 \mathrm{BL} / 6 \mathrm{~J}$ - respectively high and low stress-responsive - and studied how the differences were related to neuroendocrine and behavioral responses of the mice to emotion- and cognition-biased situations. The authors also studied how exposure to predator stress affected both behavioral and neuroendocrine responses. The study revealed intriguing relationships between the expression of the two corticosteroid receptors in brain regions typically involved in the emotion-cognition interplay (hippocampus, amygdala, and prefrontal cortex), animals' glucocorticoid reactivity, and the performance and learning strategy followed when learning a spatial task. 